OPEN ACCESS

Edited by:

Joshua Breslau,

RAND Corporation,

United States

Reviewed by:

Ali Abbas Samaha,

Lebanese International University,

Lebanon

Arash Javanbakht,

Wayne State University,

United States

${ }^{*}$ Correspondence:

Ghassan M. Issa

arcgi@mawared.org

Specialty section: This article was submitted to

Public Mental Health,

a section of the journal

Frontiers in Psychiatry

Received: 04 November 2019

Accepted: 17 March 2020

Published: 07 April 2020

Citation:

Lakkis NA, Osman MH, Aoude LC,

Maalouf CJ, Issa HG and Issa GM (2020) A Pilot Intervention to Promote

Positive Parenting in Refugees from

Syria in Lebanon and Jordan.

Front. Psychiatry 11:257.

doi: 10.3389/fpsyt.2020.00257

\section{A Pilot Intervention to Promote Positive Parenting in Refugees from Syria in Lebanon and Jordan}

\author{
Najla A. Lakkis ${ }^{1}$, Mona H. Osman ${ }^{1}$, Lara C. Aoude ${ }^{2}$, Cosette J. Maalouf ${ }^{2}$, Hanane G. Issa ${ }^{3}$ \\ and Ghassan M. Issa ${ }^{2 *}$ \\ ${ }^{1}$ Department of Family Medicine, American University of Beirut Medical Center (AUB-MC), Beirut, Lebanon, ${ }^{2}$ Arab Resource \\ Collective, Beirut, Lebanon, ${ }^{3}$ Faculty of Epidemiology and Population Health, London School of Hygiene \& Tropical Medicine, \\ London, United Kingdom
}

Background: Early childhood development (ECD) is a crucial milestone that shapes a child's health, wellbeing, education, and personality. Several factors come into play, and each requires the nurturing care of caregivers. Although the importance of ECD is well understood, the implementation of ECD programs is scarce, especially in poor and vulnerable communities.

Objective: To improve parents' wellbeing, parenting stress levels, parenting behavior, and discipline strategies after the implementation of a newly designed parenting intervention.

Participants and Setting: Parents from Syria (125 mothers and fathers) in three refugee camps in Lebanon and Jordan.

Methods: This was a pilot cohort study in which parents' wellbeing, parenting stress levels, parenting behavior, and discipline strategies were evaluated before and after participating in training in the form of interactive and educational sessions to ameliorate their relations and interactions with their children.

Results: By the end of this study, parents' mental health and wellbeing improved ( $p<$ 0.001 , Cohen's $d: 0.61)$ and their parenting index score was reduced $(p<0.001$, Cohen's $\mathrm{d}$ : 1.24). Some of their dysfunctional interactions with their children as well as the perceived difficulties and conduct problems in their children aged 3 to 6 years were also reduced significantly.

Conclusion: The intervention used in this study succeeded in improving some aspects of parenting practices and disciplines and in improving the parents' wellbeing; however, 
more research is needed to assess its long-term effects on parents and their children. Moreover, some adjustments need to be made in the intervention to be more adapted to the context of refugees and underprivileged communities.

Keywords: parenting, early childhood, parent-child interaction, refugees, stress

\section{BACKGROUND}

A child's brain grows rapidly, mostly in the first 3 to 5 years of life. Throughout this process, neural networks are molded by the interaction among genes, environment, and life experiences i.e. nature and nurture $(1,2)$.

Early child development (ECD) (i.e. from birth to 8 years) can affect significantly several aspects of the child's wellbeing, health, competence in literacy and numeracy, criminality, and social and economic participation throughout his/her lifespan (3-5). This period of life is critical to the child's development and it offers opportunities for positive guidance, healthy growth, and development that lasts a lifetime (6). Nurturing care is crucial for ECD and it includes conditions promoting "health, nutrition, security, safety, responsive caregiving, and opportunities for early learning" (3). It involves "children, their families, and other caregivers, and the places where they interact" (3).

Every child is in need of and has the right to positive responsive and engaged parenting $(2,5)$. Responsive parenting is defined as the ongoing provision of care and support that a child needs to be able to survive and thrive (6). It includes emotionally supportive, receptive, and mentally stimulating interactions, responsive feeding, and protection from threats $(3,7)$. Of these interactions, research has highlighted two parenting behaviors that are essential to children's development (7-14): (1) early and frequent participation in cognitively stimulating activities (like talking, reading, playing, and singing) to enhance a child's educational trajectory, and (2) sensitive and responsive parent-child interactions during the cognitively stimulating activities and everyday interactions. Research has also revealed that the most crucial chapter of parenting starts early during pregnancy spanning through early childhood (i.e. till the age of 6 years) and it has short and long-term repercussions on children's bio-psycho-social wellbeing including their emotions, behaviors, education, and cognitive skills $(8,11,15-17)$. Despite the solid evidence highlighting the importance of ECD, the implementation of ECD programs (i.e. initiatives that include an explicit focus on responsive caregiving and/or early learning, as defined in the 2017 Lancet series on ECD) is still scarce (18).

Parental wellbeing, family self-sufficiency, and family resilience have been reported to improve family wellbeing (FWB) including developmental parenting and child wellbeing (19). Stress (defined as coping with challenges) was shown to play a critical role in parenting as well. High levels of parenting stress have negative impacts on infants and children's outcomes (20-22). They are associated with a difficult infant temperament, higher levels of infant negative affectivity, and problems in behaviors of children aged between 3 and 9 years $(20,22)$. The levels of parenting stress are higher among families from racial and ethnic minority backgrounds (21), which is largely due to higher poverty rates (23).

Parenting practices have a significant influence on children's development as demonstrated in the literature that studied the links between parenting styles, parental discipline responses, children's behavior, and children's psychological wellbeing (24-27). Disciplining children (i.e. the process of teaching them the values and normative behaviors of their society) is one of the most important yet difficult responsibilities of parenting. Parenting programs that improve FWB and reduce parenting stress, promote different positive parenting aspects and disciplines. Such programs are needed worldwide, particularly in poor and marginalized communities.

The objectives of this pilot study are to evaluate parent wellbeing, parenting stress levels, as well as parenting behavior and discipline strategies used by refugees from Syria in bringing up their children in Lebanon and Jordan, before and after the implementation of a parenting intervention that encompasses a structured set of group training sessions and activities for parents in couples. This intervention is intended to positively influence different aspects of parenting such as disciplines and behaviors aiming at achieving positive outcomes for children in the long run. This pilot study will serve as a core element in a long-term project entitled "SANAD" i.e. SUPPORT in Arabic, which aims at training parents in couples to become master trainers and train others in a snowball team building activity.

\section{DESIGN AND METHODS}

\section{Study Design and Participants}

This pilot cohort study was conducted from June 2017 till April 2018 in three refugee camps in Lebanon (Bourj Brajneh and Shatila camps) and Jordan (Amman camp). The selected camps have been historically home to Palestinian refugees and have since 2011 become the residence of a large number of Syrian and Palestinian refugees from Syria which inflated their overcrowded living conditions. Refugees from Syria living there are generally economically vulnerable and dependent on organizations like the United Nations High Commissioner for Refugees (UNHCR), the World Food Programme (WFP), and other humanitarian organizations. This study is part of the Health, Education and Protection Parenting Project (HEPPP) managed by Arab Resource Collective (ARC) in Lebanon in coordination with Plan International (PI) in Jordan.

The target population included all refugees from Syria who satisfy the following criteria: 1) They have preschoolers (children aged 6 years or younger), 2) they are parents in couples unless 
unfeasible e.g. traveling partner, widow, divorced, 3) they understand Arabic language, and 4) they can to participate in the complete set of 21 weekly study sessions and discussions, each lasting 2 to $3 \mathrm{~h}$ (16 ECD sessions and 5 Mental Health and Psychosocial support sessions) to the best of their capabilities. Parents of children with self-reported psychotic disorder, disruptive behavioral disorder, or substance abuse were excluded from this study.

The directors of community and/or social service centers (identified as community leaders) located within each camp facilitated the recruitment process under the supervision of ARC and PI research coordinators $(\mathrm{n}=4)$. The research coordinators invited the eligible parents to participate in this study after explaining its objectives, phases, and projected benefits and risks (e.g. changing the schedule of sessions which may delay the end of the intervention). They also explained that participation is completely voluntary and that all information exchanged during the interviews will be held in strict confidentiality. Parents who accepted to participate signed an informed consent before the first interview with the coordinators. The recruitment stopped once the required convenient sample size was reached. The participants were only given the transportation fees after every session and were informed that some of them will be selected to become trainers for other parents in the second phase of the program, and will be paid per session.

A total of 125 parents (50 from Bourj Brajneh, 34 from Shatila, and 51 from Amman) were gathered and distributed as 43 couples, 33 mothers, and 6 fathers (i.e. a total of 76 mothers and 49 fathers). Around 53\% of the parents (67 parents or 42 mothers and 25 fathers) completed the study (22 from Bourj Brajneh, 12 from Shatila, and 33 from Amman), which is equivalent to 25 couples (58\%). Only one father had two wives and all of them were attending the sessions in Shatila camp. The non-couple participants were 19 mothers whose husbands were not in the same country during the intervention period. Dropout was mainly due to a change in life circumstances (e.g. finding a job) or place of living.

\section{Study Procedures and Instruments}

$\mathrm{ARC}$ and IC developed a comprehensive intervention in Arabic to positively influence parenting behaviors and achieve favorable outcomes in children. The intervention is composed of the following interactive parenting sessions: an introduction session; pregnancy: towards a healthy beginning; breastfeeding; balanced nutrition system; nutritional problems and indicators; personal hygiene (including proper bath procedures and toilet training); safety and accident prevention; immunity, infection prevention, and diseases; equity and inclusion for all children; communication with and between parents; communication with and between peers; reinforcement of positive behavior; every child has intelligence; what is your child's?; play: a child's life; critical thinking, learning, and inquiry-based skills; nursery, kindergarten and school readiness; wrapping up session; in addition to few psycho-social support sessions. The master trainers ( 1 male and 1 female in each center i.e. a total of 6), psychologists with experience in parenting training and coaching, were responsible for implementing the intervention in a very dynamic way that builds on parents' current practices and knowledge through interactive activities which include but not limited to: brainstorming activities, group work, roleplay, case study, short presentations, and open focused group discussion.

Before and at the end of the intervention, the research coordinators from ARC and PI conducted a structured interview in Arabic specially designed for this study with the recruited parents. During each interview, which lasted about one hour, the interviewer read aloud each question individually from the printed questionnaire, as some of the participants were illiterate. When any participant expressed confusion about a given question, the interviewer provided only brief explanations or elaborations, typically by paraphrasing the question. The mother and father were interviewed separately in different rooms and/or at different times so that they could not hear each other's responses. To minimize social desirability, participants were reminded during the interviews that their answers would be kept confidential, that there are no right or wrong answers to the questions, and that it is important for them to answer as honestly as possible.

The structured interview was designed by the research team at ARC based on an earlier research project entitled "Mother-Child Education Program" conducted in partnership with Yale University in the United States (Yale HSC\#1403013605). It included parents' gender, child's age, and the following instruments: World Health Organization Well-Being 5-item Index (WHO-5) (28-33); Parenting Stress Index-Short Form (PSI-SF) $(34,35)$; Strengths and Difficulties Questionnaire (SDQ) (36-43), and Parental Discipline Strategies Questionnaire (DSQ) (44) (Table 1).

\section{Data Analysis}

Data collection and entry were confidential and anonymous. The filled questionnaires were locked in a cabinet that can be accessed by research coordinators only. The Statistical Package for the Social Sciences (SPSS) version 22.0 for Windows (SPSS Inc., Chicago, IL) was used for data analysis. Cronbach's alpha coefficient $(\alpha)$ was first calculated to assess the internal consistency of each of the selected scales and subscales as a means to evaluate their reliability when utilized as continuous variables. Pre- and post-intervention data were compared using paired-samples t-test in normally distributed data or Wilcoxon signed-rank test in non-normally distributed data. The effect sizes were also calculated using Cohen's d (d) for paired t-test and $\mathrm{r}$ for with Wilcoxon test.

\section{RESULTS}

The mean age of children was 4.0 years at baseline and 4.3 years at the end of the study ( 16 children were younger than 3 years including 3 in-utero, and 49 children were between 3 and 6 years).

The overall instrument reliability was acceptable for WHO-5 ( $\alpha=0.77)$, good for PSI-SF and DSQ $(\alpha=0.83$ and 0.81 respectively), and questionable for SDQ total difficulties $(\alpha=0.62)$.

The parents' WHO-5 improved significantly after the intervention compared to baseline ( $\mathrm{p}<0.001, \mathrm{~d}$ : 0.61$)$. This 
TABLE 1 | Description of the Interview Instruments.

\begin{tabular}{|c|c|}
\hline Instrument Name & Description \\
\hline $\begin{array}{l}\text { The WHO (five) } \\
\text { Well-being Index } \\
1998 \text { version } \\
\text { (WHO-5) }\end{array}$ & $\begin{array}{l}\text { - A short } 5 \text {-item self-administered screening instrument that measures psychological well-being including depression among adults in } 2-3 \text { min. } \\
\text { - Used extensively worldwide, translated and validated into different languages, including the Arabic language. } \\
\text { Each of the } 5 \text { positively worded items is rated on a } 6 \text {-point Likert scale ranging from } 0 \text { (constantly present or all of the time) to } 5 \text { (not present } \\
\text { or at no time). The summed scores range from } 0 \text { to } 25 \text {. } \\
\text { - A score }<13 \text { indicates poor wellbeing or low mood, though not necessarily depression and warrants further assessment. }\end{array}$ \\
\hline $\begin{array}{l}\text { The Parenting } \\
\text { Stress Index-Short } \\
\text { Form (PSI-SF) }\end{array}$ & $\begin{array}{l}\text { - A 36- item self-report questionnaire of parenting stress developed from the full PSI 120-item (duration: 10-15 min). } \\
\text { - One of the most commonly used measures of parenting stress among parents of children younger than } 12 \text { years. It is validated in the Arabic } \\
\text { language. } \\
\text { - Items are rated on a 5-point Likert scale from } 1 \text { (strongly disagree) to } 5 \text { (strongly agree). } \\
\text { - It includes four subscales: Defensive Responding (DR), the Parental Distress (PD), Parent-Child Dysfunctional Interaction (PCDI) and Difficult } \\
\text { Child (DC) subscales, and a Total Stress scale with internal consistency reliability coefficients of 0.90, 0.89, 0.88, and } 0.95 \text { respectively. } \\
\text { - Higher scores indicate greater levels of parenting stress. }\end{array}$ \\
\hline $\begin{array}{l}\text { The Strengths and } \\
\text { Difficulties } \\
\text { Questionnaire } \\
\text { (SDQ) }\end{array}$ & $\begin{array}{l}\text { - A widely used brief screening questionnaire for psychosocial problems and strengths in the child's daily life. } \\
\text { - Appropriate to use in children between } 4 \text { and } 16 \text { years. } \\
\text { - The Arabic version of the Children SDQ was validated in the parents and teachers of two samples of Yemeni children. } \\
\text { It asks about } 25 \text { attributes with three response categories ( } 0=\text { not true, } 1=\text { somewhat true, and } 2=\text { certainly true), some positive and others } \\
\text { negative to cover a broad range of mental health symptoms. It includes } 5 \text { impact scales: conduct problems ( } 5 \text { items), hyperactivity-inattention } \\
\text { ( } 5 \text { items), emotional symptoms ( } 5 \text { items), and peer relationship problems ( } 5 \text { items), as well as prosocial behaviors ( } 5 \text { items). } \\
\text { - The first } 20 \text { items (i.e. without the prosocial behaviors items) are summed to create a "total difficulty" scale score ranging from } 0 \text { to } 40 \text {, with } \\
\text { "high" SDQ scores predicting much greater rates of mental disorders than "low" scores. }\end{array}$ \\
\hline $\begin{array}{l}\text { Parental Discipline } \\
\text { Strategies } \\
\text { Questionnaire } \\
\text { (DSQ) }\end{array}$ & $\begin{array}{l}\text { - It assesses } 18 \text { discipline strategies grouped into } 7 \text { discipline dimensions: inductive discipline, physical punishment, manipulation of privileges, } \\
\text { harsh verbal discipline, argument, shaming, and ignoring. } \\
\text { Parents are asked how frequently they use each of the } 18 \text { different discipline strategies in the last year on a } 5 \text {-point scale }(1=\text { never, } 2=\text { less } \\
\text { than once a month, } 3=\text { about once a month, } 4=\text { about once a week, } 5=\text { almost every day). }\end{array}$ \\
\hline & \\
\hline
\end{tabular}

References: WHO-5 (28-33), PSI-SF (34, 35), SDQ (36-43), DSQ (44).

TABLE 2 | WHO-5 Well-Being Index at baseline and after the intervention.

\begin{tabular}{|c|c|c|c|c|c|c|}
\hline & \multicolumn{2}{|c|}{ Mean (SD) } & \multicolumn{4}{|c|}{ Paired T-Test } \\
\hline & Pre & Post & $\mathbf{t}$ & df & p-value & Cohen's d \\
\hline All Children & $10.8(5.7)$ & $14.3(5.5)$ & -4 & 66 & $<.001$ & 0.61 \\
\hline Children 3 to 6 years & $10.9(5.8)$ & $14.6(5.4)$ & -4 & 49 & $<.001$ & 0.66 \\
\hline Children $<3$ years & $10.5(5.8)$ & $13.2(5.6)$ & -2 & 16 & 0.153 & 0.46 \\
\hline
\end{tabular}

A p-value less than $0.05(\leq 0.05)$ is statistically significant.

improvement remained significant in parents of children between 3 and 6 years $(\mathrm{p}<0.001, \mathrm{~d}$ : 0.66$)$, but not for parents of children younger than 3 years (Table 2 ).

The PSI-SF total score and all subscales improved significantly after the intervention compared to baseline ( $\mathrm{p}<$ $0.001, \mathrm{~d}: 1.24)$. This improvement was mostly documented in parents of children between 3 and 6 years ( $p<0.001, d: 1.31)$. Only PSI-SF total score, PCDI, and Difficult child subscales improved significantly in parents of children younger than 3 years (p: 0.006, 0.044, and 0.044 respectively; d: $1.07,0.67$, and 0.82 respectively) (Table 3 ).

The SDQ total difficulties, as well as the conduct problems and the hyperactive scales, improved significantly after the intervention compared to baseline in parents of children between 3 and 6 years ( $\mathrm{p}<0.027,0.03$ and 0.012 respectively) with moderate effect sizes (Table 3 ).

As for the Parental DSQ, the ignoring, shaming, and physical punishment scores improved significantly in parents of children between 3 and 6 years (p: 0.02, 0.30, and 0.37 respectively) with small effect sizes. There was also a trend towards improvement in the argument score in parents of children between 3 and 6 years (p: 0.050) with small effect size. A significant decline in the manipulating privileges score was found in parents of children between 3 and 6 years $(\mathrm{p}<0.001)$ with moderate to size effect size (Table 3).

Cronbach's alpha coefficient $(\alpha)$ was poor to questionable for the SDQ \& DSQ subscales, so the results per item were reported for the SDQ \& DSQ in parents of children between 3 and 6 years in the Tables 4 and 5 respectively.

\section{DISCUSSION}

Parenting practices are significant modifiable aspects of a child's home environment, which can be targeted to enhance early child development $(8,45)$. Our intervention to enhance parenting methods among refugees from Syria is the first one conducted among refugees and including couples or fathers.

As the proverb says "you cannot give what you don't have"; hence, parents' psychological wellbeing is a critical foundation to positive parenting and children's psychological wellbeing $(19,45)$. Mental health difficulties can negatively affect parenting, family functioning, and children's wellbeing and development $(46,47)$. Studies have shown also that high parenting stress has negative impacts on infants and children's outcomes (20-22, 46). This intervention improved the wellbeing of the participating refugee parents, decreased their distress, defensive responding, and dysfunctional interaction with their children, as well as their 
TABLE 3 | PSI-SF, SDQ, and DSQ scales and subscales at baseline and after the intervention.

\begin{tabular}{|c|c|c|c|c|c|c|c|c|c|c|c|}
\hline & & & \multicolumn{2}{|c|}{ Mean (SD) } & \multicolumn{4}{|c|}{ Paired T-Test } & \multicolumn{3}{|c|}{ Wilcoxon Test } \\
\hline & & & Pre & Post & $\mathbf{T}$ & df & p-value & d & $\mathbf{Z}$ & p-value & $\mathbf{r}$ \\
\hline \multirow[t]{15}{*}{ PSI-SF } & All Children & Defensive Responding & $18.9(2.8)$ & $16.6(2.7)$ & 5.431 & 66 & $<.001$ & 0.85 & & & \\
\hline & & Parental Distress & $31.9(4.5)$ & $27.8(4.2)$ & & & & & -5.362 & $<.001$ & 0.46 \\
\hline & & Parent-Child Dysfunctional Interaction & $28.4(4.0)$ & $24.9(3.3)$ & & & & & -4.645 & $<.001$ & 0.41 \\
\hline & & Difficult Child & $30.7(4.6)$ & $26.7(4.0)$ & 5.459 & 65 & $<.001$ & 0.92 & & & \\
\hline & & Total score & $91.1(9.6)$ & $79.5(9.0)$ & 7.625 & 65 & $<.001$ & 1.24 & & & \\
\hline & Children 3 to 6 yrs & Defensive Responding & $19.0(2.9)$ & $16.4(2.5)$ & 5.461 & 49 & $<.001$ & 0.98 & & & \\
\hline & & Parental Distress & $32.2(4.8)$ & $27.4(3.9)$ & & & & & -5.171 & $<.001$ & 0.52 \\
\hline & & Parent-Child Dysfunctional Interaction & $28.6(4.3)$ & $24.6(3.4)$ & 5.053 & 48 & $<.001$ & 1.03 & & & \\
\hline & & Difficult Child & $30.7(5.1)$ & $26.4(4.0)$ & 5.015 & 48 & $<.001$ & 0.95 & & & \\
\hline & & Total score & $91.8(10.7)$ & $78.5(9.4)$ & 7.114 & 48 & $<.001$ & 1.31 & & & \\
\hline & Children $<3$ yrs & Defensive Responding & $18.6(2.3)$ & $17.4(3.2)$ & 1.519 & 16 & .148 & 0.46 & & & \\
\hline & & Parental Distress & $31.1(3.5)$ & $28.9(5.2)$ & & & & & -1.354 & .176 & 0.23 \\
\hline & & Parent-Child Dysfunctional Interaction & $27.6(2.6)$ & $25.8(3.0)$ & 2.186 & 16 & .044 & 0.67 & & & \\
\hline & & Difficult Child & $30.4(2.6)$ & $27.6(4.0)$ & 2.186 & 16 & .044 & 0.82 & & & \\
\hline & & Total score & $89.2(5.4)$ & $82.4(7.2)$ & 3.198 & 16 & .006 & 1.07 & & & \\
\hline \multirow[t]{6}{*}{ SDQ } & Children 3 to 6 yrs & Emotional Problems Scale & $4.6(2.3)$ & $3.8(3.1)$ & & & & & -1.181 & .238 & 0.12 \\
\hline & & Conduct Problems Scale & $3.3(2.0)$ & $2.2(2.1)$ & & & & & -2.951 & .003 & 0.30 \\
\hline & & Hyperactive Scale & $4.9(2.4)$ & $3.9(2.4)$ & 2.607 & 48 & .012 & 0.42 & & & \\
\hline & & Peer Problems Scale & $2.9(1.7)$ & $3.3(2.3)$ & & & & & -0.837 & .403 & 0.08 \\
\hline & & Prosocial Scale & $7.9(2.0)$ & $7.9(2.8)$ & & & & & -0.929 & .353 & 0.09 \\
\hline & & Total Difficulties Score & $15.7(4.8)$ & $13.2(7.2)$ & 2.286 & 48 & .027 & 0.40 & & & \\
\hline \multirow[t]{7}{*}{ DSQ } & Children 3 to 6 yrs & Inductive Discipline score & $8.2(1.6)$ & $7.6(1.9)$ & & & & & -1.694 & .090 & 0.17 \\
\hline & & Manipulating Privileges score & $12.9(3.0)$ & $10.3(3.8)$ & 4.176 & 46 & $<.001$ & 0.75 & & & \\
\hline & & Physical Punishment score & $6.6(2.8)$ & $5.7(2.8)$ & & & & & -2.089 & .037 & 0.21 \\
\hline & & Argument score & $10.7(2.9)$ & $9.9(3.5)$ & & & & & -1.953 & .050 & 0.20 \\
\hline & & Harsh Verbal Discipline score & $6.5(2.8)$ & $6.1(2.9)$ & & & & & -1.250 & .211 & 0.13 \\
\hline & & Shaming score & $4.6(2.4)$ & $3.6(2.3)$ & & & & & -2.172 & .030 & 0.22 \\
\hline & & Ignoring score & $3.2(1.4)$ & $2.3(1.3)$ & & & & & -3.162 & .002 & 0.32 \\
\hline
\end{tabular}

PSI-SF, Parenting Stress Index-Short Form; SDQ, Strengths \& Difficulties Questionnaire; DSQ, Disciplinary Style Questionnaire.

$d=$ Cohen's $d$ (effect size for paired $t$ test); $r$ (effect size for Wilcoxon test).

A p-value less than $0.05(\leq 0.05)$ is statistically significant.

perception of their children as being difficult children. The effectiveness of group parenting programs in improving maternal psychosocial health in the short-term, including reducing stress, anxiety, and depression was reported in the literature (46). A Cochrane review showed that group-based parenting programs improve parent-child interaction in terms of a reduction in negative behaviors, and an increase in positive behaviors (46). However, these studies were conducted in developed countries and not in environments of human insecurity and displacement.

This intervention held by ARC improved the SDQ total difficulties as well as the conduct problems and the hyperactive scales of children aged 3 to 6 years as rated by their parents postintervention. In parallel to these findings, a Cochrane review presented some evidence for the use of group-based parenting programs to improve the overall emotional and behavioral adjustment of children with a maximum mean age of 3 years and 11 months, in the short-term (46).

Positive discipline styles, characterized by the presence of warm parents' behavior, provision of reasoning and explanations to children and teaching them the right behaviors, were found to be more effective in promoting strong parent-child relationship and better overall child wellbeing than negative styles characterized by punitive and power-focused behavior (19). Studies revealed also that low socioeconomic status has been associated with greater levels of harsh, physical, and inconsistent discipline (48), less responsiveness (49), and less supportive and involved parenting $(50,51)$. A group parenting intervention for Latino families minimized parents' harsh/inconsistent discipline but did not have a significant effect on their appropriate/positive discipline (52). Different systematic reviews and meta-analyses showed that parenting programs (including home-visiting programs) reduce child maltreatment as well as harsh and dysfunctional parenting practices in the short-term (53-55). Also, a brief intervention with or without a primary care visit can affect parents' attitudes by decreasing physical punishment in the short-term $(56,57)$, and improving positive parenting as well as parent-child interaction (8). Our intervention reduced mostly the ignoring, shaming, and physical punishment scores in parents of children between 3 and 6 years, with a borderline decline in the argument score. However, manipulating privileges score deteriorated after the intervention. This can be explained by the fact that the refugees have been struggling to survive since they left Syria to Lebanon and Jordan. They have had difficulties in keeping up with basic needs (shelters and food), therefore they do not possess the luxury to positively reinforce (e.g., promise a treat or privilege to the child for good behavior) or negatively punish their children (e.g., take away privileges such as watching television after dinner because of misbehavior). The 
TABLE 4 | Strengths \& Difficulties Questionnaire (SDQ).

\begin{tabular}{|c|c|c|c|c|}
\hline & \multicolumn{4}{|c|}{ Children 3 to 6 years } \\
\hline & \multicolumn{2}{|c|}{ Median (SD) } & \multicolumn{2}{|c|}{ Wilcoxon Test } \\
\hline & Pre & Post & $\mathbf{Z}$ & p-value \\
\hline \multicolumn{5}{|l|}{ Emotional problems } \\
\hline - Often complains of headaches & $1.0(0.85)$ & $0(0.91)$ & -.129 & .897 \\
\hline - Many worries & $1.0(0.75)$ & $0(0.94)$ & -1.143 & .253 \\
\hline - Often unhappy, downhearted & $1.0(0.84)$ & $1.0(0.87)$ & -.749 & .454 \\
\hline $\begin{array}{l}\text { - Nervous or clingy in new } \\
\text { situations }\end{array}$ & $1.0(0.80)$ & $0(0.91)$ & -2.663 & .008 \\
\hline $\begin{array}{l}\text { - Many fears, easily scared } \\
\text { Conduct Problems }\end{array}$ & $1.0(0.82)$ & $0(0.85)$ & -2.649 & .008 \\
\hline $\begin{array}{l}\text { - Often has temper tantrums or } \\
\text { hot tempers }\end{array}$ & $1.0(0.85)$ & $0(0.80)$ & -2.539 & .011 \\
\hline - Generally obedient & $0(0.71)$ & $0(0.77)$ & -.203 & .839 \\
\hline - Often fights with other children & $1.0(0.85)$ & $0(0.88)$ & -1.540 & .124 \\
\hline - Often lies or cheats & $0(0.71)$ & $0(0.52)$ & -1.618 & .106 \\
\hline $\begin{array}{l}\text { - Steals from home, school, or } \\
\text { elsewhere }\end{array}$ & $0(0.66)$ & $0(0.46)$ & -1.748 & .080 \\
\hline \multicolumn{5}{|l|}{ Hyperactivity } \\
\hline - Restless, overactive & $2.0(0.77)$ & $1.0(0.88)$ & -2.737 & .006 \\
\hline - Constantly fidgeting or squirming & $1.0(0.79)$ & $0(0.81)$ & -1.394 & .163 \\
\hline $\begin{array}{l}\text { - Easily distracted, concentration } \\
\text { wanders }\end{array}$ & $1.0(0.84)$ & $0(0.81)$ & -2.011 & .044 \\
\hline - Thinks things out before acting & $1.0(0.89)$ & $1.0(0.79)$ & -.557 & .577 \\
\hline - Sees tasks through to the end & $1.0(0.78)$ & $0(0.76)$ & -.841 & .400 \\
\hline $\begin{array}{l}\text { Rather solitary, tends to play } \\
\text { alone }\end{array}$ & $0(0.73)$ & $0(0.89)$ & -1.253 & .210 \\
\hline - Has at least one good friend & $0(0.77)$ & $0(0.82)$ & -.557 & .578 \\
\hline - $\quad$ Generally liked by other children & $0(0.60)$ & $0(0.69)$ & -.789 & .430 \\
\hline - $\quad$ Picked on or bullied & $0(0.83)$ & $0(0.87)$ & -.707 & .480 \\
\hline $\begin{array}{l}\text { - Gets on better with adults than } \\
\text { with other children }\end{array}$ & $1.0(0.82)$ & $2.0(0.93)$ & -.816 & .414 \\
\hline \multicolumn{5}{|l|}{ Prosocial } \\
\hline $\begin{array}{l}\text { - Considerate of other people's } \\
\text { feelings }\end{array}$ & $2.0(0.67)$ & $2.0(0.71)$ & -.269 & .788 \\
\hline - $\quad$ Shares readily with other children & $2.0(0.58)$ & $2.0(0.94)$ & -2.804 & .005 \\
\hline - Helpful if someone is hurt & $2.0(0.68)$ & $2.0(0.67)$ & -.362 & .717 \\
\hline - Kind to younger children & $2.0(0.82)$ & $2.0(0.72)$ & -.886 & .375 \\
\hline - Often volunteers to help others & $2.0(0.71)$ & $2.0(0.58)$ & -1.116 & .264 \\
\hline
\end{tabular}

A p-value less than $0.05(\leq 0.05)$ is statistically significant.

"Manipulating privileges" items should be amended to fit the life and abilities of underprivileged refugees.

\section{Limitations}

This is a pilot intervention, and the generalizability of its results is limited because some parents did not choose or were unable to participate in the parent-training intervention as offered. Socioeconomic variables were not collected. The effects of the intervention on the children were only measured indirectly through the subjective reports of the parents. Finally, it is difficult to determine whether changes are a result of the passing of time, or the intervention, as there is no control group.

\section{CONCLUSION}

Children exposed to war, forced migration, and poor living conditions are vulnerable to long-lasting negative influences and experiences that hinder proper growth and early childhood
TABLE 5 | Disciplinary Style Questionnaire (DSQ).

\begin{tabular}{|c|c|c|c|c|}
\hline \multirow[t]{3}{*}{ How frequently do you ... } & \multicolumn{4}{|c|}{ Children 3 to 6 years } \\
\hline & \multicolumn{2}{|c|}{ Median (SD) } & \multicolumn{2}{|c|}{ Wilcoxon Test } \\
\hline & Pre & Post & $\mathbf{Z}$ & p-value \\
\hline \multicolumn{5}{|l|}{ Inductive Disciplines } \\
\hline $\begin{array}{l}\text { teach your child about good \& } \\
\text { bad behavior? Like it's not nice } \\
\text { to hit, or it's polite to say thank } \\
\text { you. }\end{array}$ & $5.0(0.83)$ & $4.0(0.98)$ & -1.454 & .146 \\
\hline $\begin{array}{l}\text { - get your child to apologize or } \\
\text { make amends? }\end{array}$ & $4.0(1.26)$ & $4.0(1.22)$ & -1.726 & .084 \\
\hline \multicolumn{5}{|l|}{ Manipulating Privileges } \\
\hline $\begin{array}{l}\text { - give your child a time out or } \\
\text { send him/her to his/her room? }\end{array}$ & $3.0(1.54)$ & $2.0(1.41)$ & -1.586 & .113 \\
\hline $\begin{array}{l}\text { take away privileges? (e.g., no } \\
\text { TV after dinner because of } \\
\text { misbehavior) }\end{array}$ & $3.0(1.47)$ & $1.0(1.21)$ & -2.964 & .003 \\
\hline - give your child extra chores? & $3.5(1.55)$ & $2.0(1.71)$ & -1.883 & .060 \\
\hline $\begin{array}{l}\text { - promise a treat or privilege to } \\
\text { your child for good behavior? }\end{array}$ & $4.0(1.04)$ & $4.0(1.67)$ & -2.733 & .006 \\
\hline \multicolumn{5}{|l|}{ Physical Punishment } \\
\hline - spank, slap, or hit your child? & $2.0(1.44)$ & $1.0(1.33)$ & -3.203 & .001 \\
\hline - $\quad$ grab or shake your child? & $2.0(1.49)$ & $1.0(1.47)$ & -1.227 & .220 \\
\hline $\begin{array}{l}\text { - throw something at your child? } \\
\text { Argument }\end{array}$ & $1.0(1.14)$ & $1.0(1.33)$ & -0.833 & .405 \\
\hline argue with your child? & $4.0(1.38)$ & $4.0(1.65)$ & -1.722 & .085 \\
\hline - yell or shout at your child? & $4.0(1.12)$ & $4.0(1.53)$ & -2.067 & .039 \\
\hline $\begin{array}{l}\text { - threaten your child with some } \\
\text { punishment? }\end{array}$ & $4.0(1.46)$ & $4.0(1.42)$ & -0.652 & .514 \\
\hline \multicolumn{5}{|l|}{ Harsh Verbal Discipline } \\
\hline $\begin{array}{l}\text { - tell your child you won't love } \\
\text { him/her if she/he acts that way } \\
\text { again? }\end{array}$ & $2.0(1.42)$ & $2.0(1.65)$ & -1.163 & .245 \\
\hline - threaten to leave your child? & $1.0(1.15)$ & $1.0(1.06)$ & -1.174 & .240 \\
\hline $\begin{array}{l}\text { try to scare your child into } \\
\text { behaving (e.g., by threatening to } \\
\text { call the police, tell the teacher, } \\
\text { etc.)? }\end{array}$ & $2.0(1.55)$ & $1.0(1.19)$ & -1.678 & .093 \\
\hline \multicolumn{5}{|l|}{ Shaming } \\
\hline $\begin{array}{l}\text { say you are disappointed with } \\
\text { your child or say that his/her } \\
\text { misbehavior hurt your feelings? }\end{array}$ & $2.0(1.41)$ & $1.0(1.21)$ & -2.297 & .022 \\
\hline $\begin{array}{l}\text { tell your child } \mathrm{s} / \text { he should be } \\
\text { ashamed of her/himself? } \\
\text { lgnoring }\end{array}$ & $2.0(1.47)$ & $1.0(1.40)$ & -1.302 & .193 \\
\hline - ignore your child? & $4.0(1.43)$ & $2.0(1.31)$ & -3.162 & .002 \\
\hline
\end{tabular}

A p-value less than $0.05(\leq 0.05)$ is statistically significant.

development. Nurturing care is crucial to create a protective and responsive environment, helping children to prosper even in crisis settings.

In this pilot study, mothers and fathers in three refugee camps in Lebanon and Jordan were trained through interactive sessions that aimed at fostering their relations and interactions with their children. By the end of the program, parents experienced less distress, less defensive responding and dysfunctional parenting, and less perceived difficulties and conduct problems in children. Moreover, their mental health and wellbeing improved in the short term. However, some adjustments need to be made to the intervention tools to be better adapted to refugee and underprivileged settings. Wrap up sessions and financial incentives could decrease the rate of dropout rate. However. 
this could not be done because of the limited budget. More research is needed as well to assess the long-term effects of such interventions on early childhood development in humanitarian settings.

\section{DATA AVAILABILITY STATEMENT}

The datasets generated for this study are available on request to the corresponding author.

\section{ETHICS STATEMENT}

The studies involving human participants were reviewed and approved by the Institutional Review Board (IRB) at the American University of Beirut. The board's approval was secured before using the de-identified data for publication purposes. Parents who accepted to participate signed an informed consent form before the first interview with the coordinators.

\section{REFERENCES}

1. Center on the Developing Child. Five Numbers to Remember About Early Childhood Development (Brief). Cambridge, Massachusetts, United States: Harvard University. (2009). Retrieved from www.developingchild.harvard. edu. [accessed on 26 Jul 2018].

2. UNICEF. Early Moments Matter for Every Child. New York, NY, United States: UNICEF. (2017). https://www.unicef.org/publications/files/UNICEF_Early_ Moments_Matter_for_Every_Child.pdf [accessed on 23 Jul 2018].

3. World Health Organization. Nurturing care for early childhood development: a framework for helping children survive and thrive to transform health and human potential. Geneva, Switzerland (2018). https://apps.who.int/iris/bitstream/handle/ 10665/272603/9789241514064-eng.pdf. [accessed on 30 May 2019].

4. High PC and American Academy of Pediatrics Committee on Early Childhood, Adoption, and Dependent Care and Council on School Health. Adoption, and Dependent Care and Council on School Health. School readiness. Pediatrics (2008) 121(4) e1008-18. Available at: www.pediatrics.org/cgi/content/full/121/4/e1008.

5. Morrison J, Pikhart H, Ruiz M, Goldblatt P. Systematic review of parenting interventions in European countries aiming to reduce social inequalities in children's health and development. BMC Public Health (2014) 14:1040. doi: 10.1186/1471-2458-14-1040

6. UNICEF. Early childhood. Parenting Programmes. UNICEF. (2012). [accessed on 07 Oct 2017].

7. Britto PR, Lye SJ, Proulx K, Yousafzai AK, Matthews SG, Vaivada T, et al. Nurturing care: promoting early childhood development. Lancet (2017) 389 (10064):91-102. doi: 10.1016/S0140-6736(16)31390-3

8. Shah R, Kennedy S, Clark MD, Bauer SC, Schwartz A. Primary Care-Based Interventions to Promote Positive Parenting Behaviors: A Meta-analysis. Pediatrics (2016) 137(5):pii: e20153393. doi: 10.1542/peds.2015-3393

9. Tamis-LeMonda CS, Shannon JD, Cabrera NJ, Lamb ME. Fathers and mothers at play with their 2- and 3-year-olds: contributions to language and cognitive development. Child Dev (2004) 75(6):1806-20. doi: 10.1111/j.1467-8624.2004.00818.x

10. Eshel N, Daelmans B, de Mello MC, Martines J. Responsive parenting: interventions and outcomes. Bull World Health Organ (2006) 84(12):991-8. doi: 10.2471/BLT.06.030163

11. Landry SH, Smith KE, Swank PR. The importance of parenting during early childhood for school-age development. Dev Neuropsychol (2003) 24(23):559-91. doi: 10.1080/87565641.2003.9651911

12. Larson K, Russ SA, Nelson BB, Olson LM, Halfon N. Cognitive ability at kindergarten entry and socioeconomic status. Pediatrics (2015). Available at:

\section{AUTHOR CONTRIBUTIONS:}

GI, LA, and CM designed the intervention, developed the intervention materials, and coordinated its implementation. NL analyzed and interpreted the data. NL, MO, and HI wrote the manuscript. All authors read and approved the final manuscript.

\section{FUNDING}

This work was supported by the Early Childhood Program, Open Society Foundation, London. The funding source did not contribute to the design of the intervention, the data collection, analysis, or write-up of the results.

\section{ACKNOWLEDGMENTS}

The authors would like to thank the team of Arab Resource Collective (ARC) in Lebanon and Plan International (PI) in Jordan for their efforts in the implementation of this intervention.

www.pediatrics.org/cgi/content/full/135/2/e440. 135(2):e440-48. doi: 10.1542/peds.2014-0434

13. Rodriguez ET, Tamis LeMonda CS, Spellmann ME, et al. The formative role of home literacy experiences across the first three years of life in children from low-income families. J Appl Dev Psychol (2009) 30(6):677-94. doi: 10.1016/j.appdev.2009.01.003

14. Lugo-Gil J, Tamis-LeMonda CS. Family resources and parenting quality: links to children's cognitive development across the first 3 years. Child Dev (2008) 79(4):1065-85. doi: 10.1111/j.1467-8624.2008.01176.x

15. Scott S. Parenting quality and children's mental health: biological mechanisms and psychological interventions. Curr Opin Psychiatry (2012) 25(4):301-6. doi: 10.1097/YCO.0b013e328354a1c5

16. Shonkoff JP, Garner ASCommittee on Psychosocial Aspects of Child and Family Health; Committee on Early Childhood, Adoption, and Dependent Care; Section on Developmental and Behavioral Pediatrics. The lifelong effects of early childhood adversity and toxic stress. Pediatrics (2012) 129(1):e232-46. doi: 10.1542/peds.2011-2663

17. Hensch TK. Critical period plasticity in local cortical circuits. Nat Rev Neurosci (2005) 6(11):877-88. doi: 10.1038/nrn1787

18. Murphy KM, Yoshikawa H, Wuermli AJ. Implementation research for early childhood development programming in humanitarian contexts. Ann NY Acad Sci (2018) 1419(1):90-101. doi: 10.1111/nyas.13691

19. Newland LA. Family well-being, parenting, and child well-being: Pathways to healthy adjustment. Clin Psychol (2015) 19(1):3-14. doi: 10.1111/cp.12059

20. Chang Y, Fine MA, Ispa J, Thornburg KR, Sharp E, Wolfenstein M. Understanding parenting stress among young, low-income, African-American, first-time mothers. Early Educ Dev (2004) 15:265-82. doi: 10.1207/s15566935eed1503_2

21. Franco LM, Pottick K, Huang CC. Early parenthood in a community context: Neighborhood conditions, race-ethnicity, and parenting stress. J Community Psychol (2010) 38:574-90. doi: 10.1002/jcop.20382

22. Neece CL, Green SA, Baker B. Parenting stress and child behavior problems: a transactional relationship across time. Am J Intellectual Dev Disabil (2012) 117(1):48-66. doi: 10.1352/1944-7558-117.1.48

23. Huston AC, McLoyd VC, Garcia Coll C. Children and poverty: Issues in contemporary research. Child Dev (1994) 65:275-82. doi: 10.1111/j.14678624.1994.tb00750.x

24. Smith AB, Gollop M, Taylor NJ, Marshall K. The discipline and guidance of children: A summary of research. Dunedin and Wellington, NZ: Children's Issues Centre and Office of the Commissioner for Children (2005).

25. Parke RD. Punishment revisited-science, values, and the right question: comment on Gershoff (2002). Psychol Bull (2002) 128(4):596-601; discussion 602-11. doi: 10.1037/0033-2909.128.4.596 
26. Gershoff ET. Corporal punishment by parents and associated child behaviors and experiences: A meta-analytic and theoretical review. psychol Bull (2002) 128:539-79. doi: 10.1037/0033-2909.128.4.539

27. Eisenberg N, Losoya S, Fabes RA, Guthrie IK, Reiser M, Murphy B, et al. Parental socialization of children's dysregulated expression of emotion and externalizing problems. J Fam Psychol (2001) 15(2):183-205. doi: 10.1037/0893-3200.15.2.183

28. World Health Organization (WHO). Wellbeing Measures in Primary Health Care. Regional Office for Europe, Copenhagen: The DepCare Project. WHO (1998a).

29. World Health Organization (WHO). Info Package: Mastering Depression in Primary Care, Version 2.2. Regional Office for Europe, Copenhagen: WHO (1998b).

30. Bech P, Gudex C, Staehr Johansen K. The WHO (Ten) Well-Being Index: Validation in Diabetes. Psychother Psychosom (1996) 65:183-90. doi: 10.1159/ 000289073

31. Topp CW, Østergaard SD, Søndergaard S, Bech P. The WHO-5 Well-Being Index: a systematic review of the literature. Psychother Psychosom (2015) 84 (3):167-76. doi: 10.1159/000376585

32. Sibai AM, Chaaya M, Tohme RA, Mahfoud Z, Al-Amin H. Validation of the Arabic version of the 5-item WHO Well Being Index in elderly population. Int J Geriatr Psychiatry (2009) 24(1):106-7. doi: 10.1002/gps.2079

33. Henkel V, Mergl R, Kohnen R, Maier W, Möller H-J, Hegerl U. Identifying depression in primary care: a comparison of different methods in a prospective cohort study. BMJ Br Med J (2003) 326(7382):200-1. doi: 10.1136/bmj.326.7382.200

34. Abidin RR. Parenting Stress Index. Odessa, FL: Psychological Assessment Resources (2012).

35. Dardas L, Ahmad M. Psychometric properties of the Parenting Stress Index with parents of children with autistic disorder. J Intellect Disabil Res (2014) 58 (6):560-71. doi: 10.1111/jir.12053

36. Goodman R. The Strengths and Difficulties Questionnaire: a research note. $J$ Child Psychol psychiatry Allied disciplines (1997) 38(5):581-6. doi: 10.1111/ j.1469-7610.1997.tb01545.x

37. Goodman R. The extended version of the Strengths and Difficulties Questionnaire as a guide to child psychiatric caseness and consequent burden. J Child Psychol psychiatry Allied disciplines (1999) 40(5):791-9. doi: 10.1111/1469-7610.00494

38. Goodman R. Psychometric properties of the strengths and difficulties questionnaire. J Am Acad Child Adolesc Psychiatry (2001) 40:1337-45. doi: 10.1097/00004583-200111000-00015

39. Stone LL, Otten R, Engels RCME, Vermulst AA, Janssens JMAM. Psychometric Properties of the Parent and Teacher Versions of the Strengths and Difficulties Questionnaire for 4- to 12-Year-Olds: A Review. Clin Child Family Psychol Rev (2010) 13(3):254-74. doi: 10.1007/s10567-010-0071-2

40. Croft S, Stride C, Maughan B, Rowe R. Validity of the strengths and difficulties questionnaire in preschool-aged children. Pediatrics (2015) 135(5):e1210-9. doi: 10.1542/peds.2014-2920

41. Marquis RA, Flynn RJ. The SDQ as a mental health measurement tool in a Canadian sample of looked-after young people. Vulnerable Child Youth Stud (2009) 4:114-21. doi: 10.1080/17450120902887392

42. Goodman A, Goodman R. Strengths and Difficulties Questionnaire as a dimensional measure of child mental health. J Am Acad Child Adolesc Psychiatry (2009) 48:400-3. doi: 10.1097/CHI.0b013e3181985068

43. Alyahri A, Goodman R. Validation of the Arabic Strengths and Difficulties Questionnaire and the Development and Well-Being Assessment. East Mediterr Health J (2006) 12(Suppl;2):S138-46.

44. Huang L, Malone PS, Lansford JE, Deater-Deckard K, Di Giunta L, Bombi AS, et al. Measurement Invariance of Discipline in Different Cultural Contexts. Fam Sci (2011) 2(3):212-9. doi: 10.1080/19424620.2011.655997
45. Barlow J, Bergman H, Kornør H, Wei Y, Bennett C. Group-based parent training programmes for improving emotional and behavioural adjustment in young children. Cochrane Database Syst Rev (2016) (8):CD003680. doi: 10.1002/14651858.CD003680.pub3

46. Barlow J, Smailagic N, Huband N, Roloff V, Bennett C. Group-based parent training programmes for improving parental psychosocial health. Cochrane Database Syst Rev (2014) (5):CD002020. doi: 10.1002/14651858.CD002020.pub4

47. Goodman SH, Gotlib IH. Risk for psychopathology in the children of depressed mothers: A developmental model for understanding mechanisms of transmission. Psychol Rev (1999) 106(3):458-90. doi: 10.1037/0033-295X

48. Pinderhughes EE, Dodge KA, Bates JE, Pettit GS, Zelli A. Discipline responses: Influences of parents' socioeconomic status, ethnicity, beliefs about parenting, stress, and cognitive-emotional processes. J Fam Psychol (2000) 14:380-400. doi: 10.1037/0893-3200.14.3.380

49. McLeod JD, Shanahan MJ. Poverty, parenting, and children's mental health. Am Sociol Rev (1993) 58:351-66. doi: 10.2307/2095905

50. Brody GH, Murry VMB, Kim S, Brown AC. Longitudinal pathways to competence and psychological adjustment among African American children living in rural single-parent households. Child Dev (2002) 73:1505-16. doi: 10.1111/1467-8624.00486

51. Shelleby EC, Shaw DS. Outcomes of Parenting Interventions for Child Conduct Problems: A Review of Differential Effectiveness. Child Psychiatry Hum Dev (2014) 45(5):628-45. doi: 10.1007/s10578-013-0431-5

52. Dumas JE, Arriaga X, Begle AM. Child and parental outcomes of a group parenting intervention for Latino families: A pilot study of the CANNE program. Cultural Diversity ethnic minority Psychol (2011) 17(1):107-15. doi: $10.1037 / \mathrm{a} 0021972$

53. Vlahovicova K, Melendez-Torres GJ, Leijten P, Knerr W, Gardner F. Parenting Programs for the Prevention of Child Physical Abuse Recurrence: A Systematic Review and Meta-Analysis. Clin Child Family Psychol Rev (2017) 20(3):351-65. doi: 10.1007/s10567-017-0232-7

54. Chen M1, Chan KL. Effects of Parenting Programs on Child Maltreatment Prevention: A Meta-Analysis. Trauma Violence Abuse (2016) 17(1):88-104 doi: $10.1177 / 1524838014566718$

55. Avellar SA, Supplee LH. Effectiveness of home visiting in improving child health and reducing child maltreatment. Pediatrics (2013) 132(Suppl;2):S909. doi: 10.1542/peds.2013-1021G

56. Scholer SJ, Hamilton EC, Johnson MC, Scott TA. A brief intervention may affect parents' attitudes toward using less physical punishment. Fam Community Health (2010) 33(2):106-16. doi: 10.1097/FCH.0b013e3181d592ef

57. Chavis A, Hudnut-Beumler J, Webb MW, Neely JA, Bickman L, Dietrich MS, et al. A brief intervention affects parents' attitudes toward using less physical punishment. Child Abuse Negl (2013) 37(12):1192-201. doi: 10.1016/ j.chiabu.2013.06.003

Conflict of Interest: The authors declare that the research was conducted in the absence of any commercial or financial relationships that could be construed as a potential conflict of interest.

Copyright (c) 2020 Lakkis, Osman, Aoude, Maalouf, Issa and Issa. This is an openaccess article distributed under the terms of the Creative Commons Attribution License (CC BY). The use, distribution or reproduction in other forums is permitted, provided the original author(s) and the copyright owner(s) are credited and that the original publication in this journal is cited, in accordance with accepted academic practice. No use, distribution or reproduction is permitted which does not comply with these terms. 